\title{
Role of the Enterotoxic Hemolysin in Pathogenicity of Vibrio mimicus
}

\section{Tao Li, Akiko Kobayashi, Noriko Takata, Tomonaga Yoshimura, Yoko Maehara, Tomofusa Tsuchiya, and Shin-ichi Miyoshi*}

Graduate School of Medicine, Dentistry and Pharmaceutical Sciences, Okayama University, Tushima-Naka, Okayama 700 8530, Japan

(Received August 1, 2008; Accepted August 25, 2008; Published online August 27, 2008)

Vibrio mimicus ( $V$. mimicus) is a causative agent of human gastroenteritis and food poisoning. Although several toxic or virulence factors have been isolated from the bacterium, an enterotoxic hemolysin is a sole toxin produced by all clinical isolates. In the present study, we found that the antibody against the hemolysin significantly inhibited the fluidaccumulating action of the living cells inoculated into a rabbit ileal loop, and that the hemolysin gene $(v m h A)$ was probably expressed by the bacterium in the ileal loop. Additionally, in spit of the comparable motility and similar proteome profiles, a vmhA mutant revealed the reduced fluid-accumulating activity. Theses findings suggest that the hemolysin contributes to full virulence of $V$. mimicus.

Key words — Vibrio mimicus, hemolysin, virulence factor

\section{INTRODUCTION}

Vibrio mimicus (V. mimicus) is a Gram-negative bacterium closely similar to Vibrio cholerae (V. cholerae) causing epidemic cholera, while this species is an etiologic agent of sporadic acute human gastroenteritis and food poisoning. ${ }^{1,2)} \mathrm{Al}$ though production of several kinds of protein toxins by the bacterium has been documented, $\left.{ }^{2,3}\right)$ an enterotoxic hemolysin designated $V$. mimicus hemolysin $(\mathrm{VMH})^{4)}$ may be a primary candidate

\footnotetext{
*To whom correspondence should be addressed: Graduate School of Medicine, Dentistry and Pharmaceutical Sciences, Okayama University, Tsushima-Naka, Okayama 700-8530, Japan. Tel. \& Fax: +81-86-251-7966; E-mail: miyoshi@ pharm. okayama-u.ac.jp
}

of a virulence determinant. For instance, Shinoda et $a l^{5)}$ documented that the gene encoding $\mathrm{VMH}$, but not other toxins, is present in all strains isolated from various clinical and environmental specimens. VMH is secreted from the bacterial cell as an $80-\mathrm{kDa}(80399 \mathrm{Da})$ precursor and, in turn, converted to a $66-\mathrm{kDa}(65997 \mathrm{Da})$ mature form through proteolytic removal of a $\mathrm{N}$-terminal propeptide. ${ }^{6)}$ When administrated into a rabbit ligated ileal loop, the mature toxin elicits the fluid accumulation (FA) in a dose-dependent manner. ${ }^{4)}$ Recent in vitro experiments using cultured mammalian cells revealed that the FA by VMH might be linked to activation of the cyclic adenosine $5^{\prime}$-monophosphate (AMP)dependent and $\mathrm{Ca}^{2+}$-dependent $\mathrm{Cl}^{-}$secretory pathways. ${ }^{7,8)}$ In order to verify the importance of VMH as a virulence determinant, we herein studied the inhibitory effect of the specific anti-VMH antibody on the FA caused by $V$. mimicus living cells and the possible expression of the hemolysin gene (vmhA) in the ileal loop. Furthermore, we constructed a $v m h A$-negative mutant and carried out its characterization including the FA ability.

\section{MATERIALS AND METHODS}

Bacterial Strains — V. mimicus strains CS-5 and CS-20, which were isolated from patients suffering from gastroenteritis in India and Japan respectively, were used in the present study. The vmhA mutants, TKT1, TKT2 and TKT3, were constructed from strain CS-20 through the single crossover homologous recombination technique as described by Nishibuchi et al. ${ }^{9)}$

The Ligated Ileal Loop Test — The ligated ileal loop test to evaluate the enteropathogenicity of the living cells was carried out with an anesthetized male Japanese White rabbit $(1.8 \mathrm{~kg})$ as reported. $\left.{ }^{4}\right)$ Briefly, V. mimicus was cultivated at $37^{\circ} \mathrm{C}$ for 5-6 hr in heart infusion broth (Becton, Dickinson and Company, Franklin Lakes, NJ, U.S.A.), and the bacterial cells were harvested by centrifugation $(7000 \times g, 30 \mathrm{~min})$ and suspended into DHIB, heart infusion broth diluted 10-fold with PBS $(20 \mathrm{mM}$ phosphate buffer containing $0.9 \% \mathrm{NaCl}, \mathrm{pH} 6.8$ ), at a cell density of $2 \times 10^{9} \mathrm{cell} / \mathrm{ml}$. The cell suspension prepared $(0.5 \mathrm{ml})$ was mixed with $0.5 \mathrm{ml}$ of PBS, the IgG antibody against purified VMH $(450 \mu \mathrm{g} / \mathrm{ml})$, or control IgG $(450 \mu \mathrm{g} / \mathrm{ml})$. Thereafter, the admixture was injected into the ileal loop, and the extent of FA was observed at $16-\mathrm{hr}$ postinjection. The FA activ- 
ity was expressed as the ratio of fluid volume (ml) per loop length $(\mathrm{cm})$.

Expression of the vmhA Gene- The expression of $v m h A$ was studied by reverse transcription (RT)-PCR with primers VMH-P1 (5'GGACATGACAAACAAACCGG-3') and VMHP2 (5'-GCGATCTTCATGAGCATTGC-3'), which correspond respectively to bases at 2493-2512 and 2884-2903 of the vmhA gene (GenBank Accession No. U68271). The bacterial cells in DHIB $\left(1 \times 10^{9} \mathrm{cell} / \mathrm{ml}\right)$ was cultivated at $37^{\circ} \mathrm{C}$ for $16 \mathrm{hr}$ without shaking, and total RNA was isolated with Sepasol-RNA I Super (Nacalai tesque, Kyoto, Japan) according to the manufacturer's manual. The total RNA thus obtained was added to the Ready-to-Go RT-PCR Kit (GE Healthcare Biosciences, Piscataway, NJ, U.S.A.) and incubated at $42^{\circ} \mathrm{C}$ for $30 \mathrm{~min}$ for reverse transcription. Thereafter, the reverse transcriptase was inactivated by heating at $95^{\circ} \mathrm{C}$ for $5 \mathrm{~min}$, and PCR was carried out for 30 cycles as follows; $30 \mathrm{~s}$ denaturation at $95^{\circ} \mathrm{C}$, $30 \mathrm{~s}$ annealing at $60^{\circ} \mathrm{C}$, and $1 \mathrm{~min}$ extension at $72^{\circ} \mathrm{C}$. The PCR products (401-bp) were subjected to electrophoresis with $1.5 \%$ agarose gel and visualized by staining with ethidium bromide.

The Motility Test — The semisolid agar medium (DHIB supplemented with $0.3 \%$ agar, $\mathrm{pH}$ 6.8) was prepared in a U-shaped tube. The bacterium was inoculated on the top of the medium and cultivated at $37^{\circ} \mathrm{C}$ without shaking. At an appropriate cultivation period, the bacterial motility $(\mathrm{mm} / \mathrm{h})$ was measured.

Extracellular Proteins and Outer Membrane Proteins — To prepare the sample of the extracellular proteins, the bacterial cells in DHIB $\left(1 \times 10^{9} \mathrm{cell} / \mathrm{ml}\right)$ was cultivated at $37^{\circ} \mathrm{C}$ for $16 \mathrm{hr}$ without shaking. The culture supernatant was collected by centrifugation $(7000 \times \mathrm{g}, 30 \mathrm{~min})$ and concentrated through fractionation with $80 \%$ saturated ammonium sulfate.

To prepare the sample of the outer membrane proteins, after cultivation at $37^{\circ} \mathrm{C}$ for $16 \mathrm{hr}$ in DHIB, the bacterial cells were harvested and disrupted by the repeated freezing and thawing. The outer membrane was collected by treatment with $1 \%$ Sarkosyl followed by centrifugation $\left.(100000 \times g, 60 \mathrm{~min}),{ }^{10}\right)$ and then, the membrane preparation was mixed with an equal volume of $125 \mathrm{mM}$ Tris- $\mathrm{HCl}$ buffer containing $2 \%$ sodium dodecyl sulfate (SDS), $20 \%$ grycerol and $0.05 \%$ bromophenol blue $(\mathrm{pH} 6.8)$. Thereafter, the outer membrane proteins were solubilized by heat treatment at $100^{\circ} \mathrm{C}$ for $5 \mathrm{~min}$, and to remove SDS, the solubilized proteins were pre- cipitated by the addition of 5\% trichloroacetic acid and rinsed with acetone. Then, the outer membrane proteins isolated were dissolved into the mixture of $60 \mathrm{mM}$ Tris, $5 \mathrm{M}$ urea, $1 \mathrm{M}$ thiourea, $1 \%$ CHAPS and $1 \%$ Triton $\mathrm{X}-100$.

Two-Dimensional Gel Electrophoresis — First, the sample $(50 \mu \mathrm{g})$ was subjected to isoelectric focusing using the discRun AE-6541 system with the agar GEL pH 3-10 (ATTO, Tokyo, Japan). After the electrophoresis at $300 \mathrm{~V}$ for $3.5 \mathrm{hr}$, the gel was treated with $2.5 \%$ trichloroacetic acid for $3 \mathrm{~min}$ and soaked in distilled water for $2 \mathrm{hr}$. Thereafter, it was treated with $2 \%$ SDS in $50 \mathrm{mM}$ Tris- $\mathrm{HCl}(\mathrm{pH} 6.8)$ at room temperature for $10 \mathrm{~min}$ and subjected to SDSpolyacrylamide gel electrophoresis (PAGE) using the pageRun AE6531 system with the e-PAGEL 5$20 \%$ (ATTO). After the electrophoresis at $20 \mathrm{~mA}$ for $80 \mathrm{~min}$, the gel was rinsed with $7.5 \%$ acetic acid-5\% ethanol and stained with $0.1 \%$ Coomassie Brilliant Blue R-250.

For identification of the protein, an appropriate protein was picked up from the gel and treated with the Protein In-Gel Tryptic Digestion Kit (Agilent Technologies, Santa Clara, CA, U.S.A.) according to the manufacturer's manual. Then, the protein fragments generated were analyzed with the Nanoflow LC/MS System (Agilent Technologies).

\section{RESULTS AND DISCUSSION}

\section{In vivo and in vitro Experiments with Clinical Isolates}

Purified VMH has been reported to elicit the FA in an animal ileal loop. ${ }^{4}{ }^{4)}$ To test the FA activity of living $V$. mimicus cells, the rabbit ileal loop test was carried out. Two clinical strains (CS-5 and CS-20) were injected into the ileal loop, and the FA activity was measured at 16-hr postinjection. As well as the purified toxin, the living cells of either strain caused steady accumulation of slightly bloody fluid into the ileal loop (Fig. 1). Next, we tested the neutralizing effect of the IgG antibody against purified VMH. This antibody was highly specific because, in Western blot analysis of the culture supernatant, only the VMH antigen was reacted with the antibody. ${ }^{6)}$ As shown in Fig. 1, the antibody significantly $(p<0.05)$ neutralized the FA ability of either strain. Namely, the FA by strain CS-5 and CS-20 were respectively reduced to $42 \%$ and $48 \%$ by the addition of the anti-VMH antibody. We previously documented that the FA ability of a highly entero- 


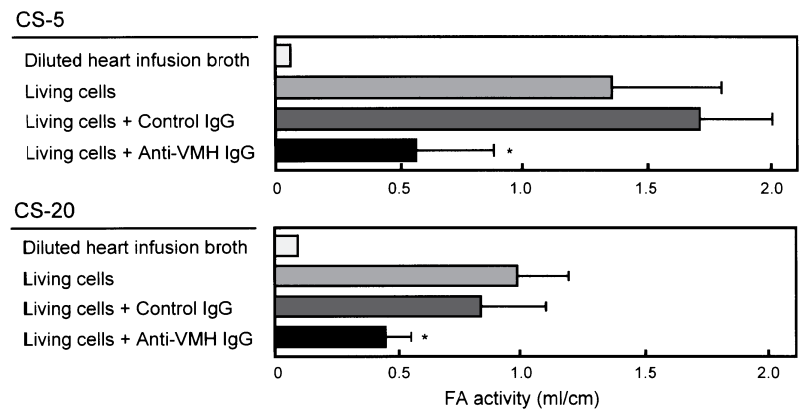

Fig. 1. Fluid Accumulation Elicited by V. mimicus Living Cells and Its Neutralization by the Antibody against $\mathrm{VMH}$

The bacterial cells in 10-fold diluted heart infusion broth ( $\mathrm{pH} 6.8$ ) were mixed with saline, anti-VMH IgG or control IgG. Each of the admixtures was injected into an ileal loop, and FA was measured at 16-hr postinjection. Each value represents the mean and S.D. of five experiments. $*, p<0.05$.

toxicgenic environmental isolate, strain E-33, was markedly abolished by the antibody against $\mathrm{VMH} .{ }^{4)}$ The anti-VMH antibody also showed the comparable neutralizing effect in the present study using clinical strains. These findings strongly support the conclusion that VMH is a major enterotoxic factor produced by $V$. mimicus.

For in vitro multiplication under the mimic condition of the ileal loop, the bacterial cells were suspended into DHIB $\left(1 \times 10^{9}\right.$ cell $\left./ \mathrm{ml}\right)$ and cultivated at $37^{\circ} \mathrm{C}$ for $16 \mathrm{hr}$ without shaking, and both the bacterial cells and culture supernatant were collected. First, expression of the $v m h A$ gene was studied by RT-PCR using a total RNA preparation from the bacterial cells. In both strain CS-5 and CS-20, the single 401-bp amplicon was detected when the RT-PCR products were subjected to electrophoresis. Next, production of active VMH was examined by measuring the hemolytic activity of the culture supernatant. The sample from either strain showed the significant hemolytic activity (about 55 unit $/ \mathrm{ml}$ ) when allowed to act on horse erythrocytes. These results suggest expression of the $v m h A$ gene and production of active VMH in the ileal loop. However, since pathogenic as well as commensal bacteria are known to express different sets of genes in the gastrointestinal tract, ${ }^{11,12)}$ the follow-up experiments using the bacterial cells recovered from the loop fluids may be needed to confirm the in vivo expression of the $v m h A$ gene.

\section{Construction and Selection of a $v m h A$ Mutant TKT-2}

In order to clarify the pathological role of $\mathrm{VMH}, v m h A$-negative mutants were constructed
Table 1. Motility and Enteropathogenicity of V. mimicus Strains

\begin{tabular}{ccc}
\hline \hline Strain & $\begin{array}{c}\text { Motility } \\
(\mathrm{mm} / \mathrm{h})^{a)}\end{array}$ & $\begin{array}{c}\text { Fluid accumulation } \\
\left.(\mathrm{ml} / \mathrm{cm})^{a}\right)\end{array}$ \\
\hline CS-20 & $1.53 \pm 0.11$ & $0.76 \pm 0.14$ \\
TKT-1 & $1.20 \pm 0.12^{b)}$ & N.T. ${ }^{c)}$ \\
TKT-2 & $1.59 \pm 0.13$ & $0.28 \pm 0.25^{b)}$ \\
TKT-3 & $1.08 \pm 0.04^{b)}$ & N.T. ${ }^{c)}$ \\
\hline
\end{tabular}

a) Each value represents the mean and S.D. of five experiments. b) $p<0.05$. $c$ ) Not tested.

from strain CS-20 through the homologous recombination technique, ${ }^{9)}$ in which a suicide vector containing a chloramphenicol resistance gene was used. The 0.9-kb fragment of the $v m h A$ gene was ligated to the suicide vector, and the hybrid plasmid constructed was transferred to Escherichia coli (E. coli). Thereafter, for conjugation, the transformant was incubated with $V$. mimicus strain CS-20 at $20^{\circ} \mathrm{C}$ for $24 \mathrm{hr}$. Three mutants (TKT-1, TKT2 and TKT-3) showing the chloramphenicol resistance and forming no hemolytic zone on the blood agar plate (Nissui Pharmaceutical, Tokyo, Japan) were isolated. Southern blot analysis of the mutants evidently revealed disruption of the $v m h A$ gene through insertion of the hybrid plasmid. Namely, when the digoxigenin-labeled probe for $v m h A$ was allowed to act on chromosomal DNA digested with SalI and PstI, the 5.5-kb DNA fragment reacting with the probe was recognized in the wild type strain while the larger $8.0-\mathrm{kb}$ fragment was detected in the mutants.

In human pathogenic Vibrio species including $V$. cholerae, the motility is essential for full virulence. ${ }^{13,14)}$ However, it was suspected that the lessmotility clones might have the advantage of conjugation with $E$. coli transformant. Therefore, the motility test using a semisolid agar medium was carried out. Among the mutants, strain TKT-2 revealed an equal motility to strain CS-20, but strain TKT-1 and TKT-3 showed the reduced motility (Table 1). Strain TKT-2 was further demonstrated to have the comparable viability in DHIB. In both strain CS-20 and TKT-2, no significant decrease in the bacterial cell numbers was observed after cultivation at $37^{\circ} \mathrm{C}$ for $16 \mathrm{hr}$ in DHIB (data not shown). Hence, only strain TKT-2 was selected and used in the following experiments.

\section{Characterization of a $\boldsymbol{v m h A}$ Mutant TKT-2}

Since artificial disruption of a functional gene may cause transcription of a silent gene, ${ }^{15,16)}$ the profiles of extracellular and outer membrane pro- 

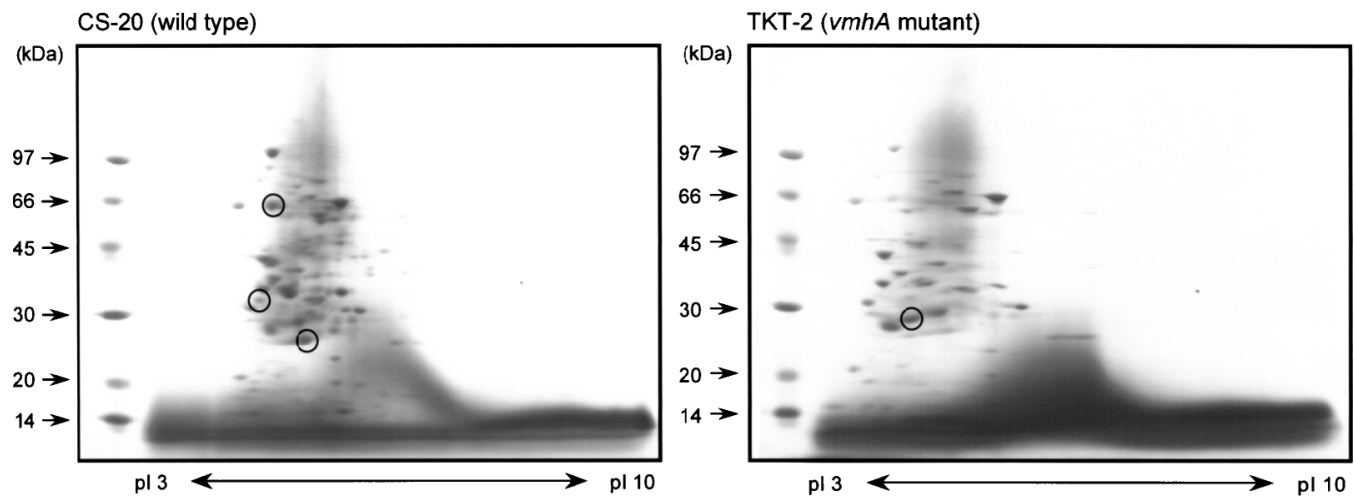

Fig. 2. Profiles of Extracellular Proteins Isolated by Two-Dimensional Gel Electrophoresis

The sample $(50 \mu \mathrm{g})$ from $V$. mimicus strain CS-20 or TKT-2 was separated by isoelectric focusing followed by SDS-PAGE and stained with $0.1 \%$ Coomassie Brilliant Blue R-250, and proteins marked with a circle were subjected to LC/MS analysis. The sample from strain CS-20 contained about 50 units $(0.5 \mu \mathrm{g})$ of $\mathrm{VMH}$; however, the spot of VMH could not be identified.
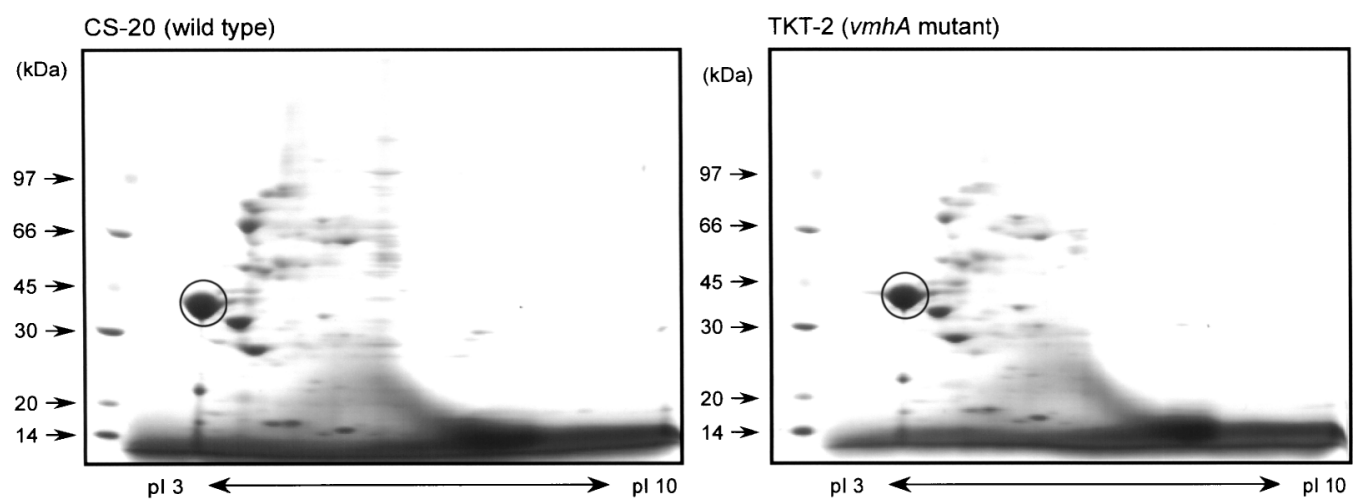

Fig. 3. Profiles of Outer Membrane Proteins Isolated by Two-Dimensional Gel Electrophoresis

The sample $(50 \mu \mathrm{g})$ from $\mathrm{V}$. mimicus strain CS-20 or TKT-2 was separated by isoelectric focusing followed by SDS-PAGE, and stained with $0.1 \%$ Coomassie Brilliant Blue R-250. The proteins marked with a circle are a 39-kDa major outer membrane protein mediating attachment of the bacterial cell. ${ }^{17,19)}$

teins of strain TKT-2 were compared with those of strain CS-20. The sample of the extracellular proteins prepared from the 16-hr culture supernatant was subjected to isoelectric focusing followed by SDS-PAGE, and the profiles of proteins separated were compared. The overall protein profiles were similar each other, whereas the amounts of some proteins were increased or decreased in the mutant (Fig. 2). However, these proteins could not be identified by liquid chromatography (LC)/MS analysis because no genomic database for V. mimicus is available. Also, no presumed homologue was determined from the databases of other Vibrio species including $V$. cholerae. Therefore, the proteins analyzed may be not products of $V$. mimicus cells. Previously, our group has documented that $V$. mimicus may attach to the intestinal mucosa via outer membrane proteins ${ }^{17)}$ and that the intestinal adhesiveness of the bacterium may correlate with pathogenicity. ${ }^{18)}$ So that, the profiles of outer membrane proteins were also compared. As shown in Fig. 3, in two-dimensional gel electrophoresis, no remarkable difference in the protein profiles including a $39-\mathrm{kDa}$ major outer membrane proteins mediating bacterial attachment ${ }^{17,19)}$ was observed. These findings suggest that disruption of the $v m h A$ gene does not trigger expression of the genes, which encode extracellular or cell-associated proteins but are silent in the wild type strain.

As anticipated, a $v m h A$ mutant TKT-2 showed significantly reduced FA activity when inoculated into the ileal loop (Table 1). Therefore, it was verified that VMH had an important role in pathogenicity of $V$. mimicus. However, it should be noted that the mutant revealed variable FA activity $(0.0-0.60)$. By contrast, the wild type strain constantly showed the high activity (0.56-0.94). The variability of the FA activity observed suggests that $V$. mimicus may contain an additional virulence determinant(s) of which expression level is depend on the experi- 
mental condition.

Although $V$. mimicus has been reported to produce several extracellular toxic factors, ${ }^{2,3)} \mathrm{VMH}$ is an unique factor elaborated by all clinical isolates. ${ }^{5}$ The present study supports the current opinion that VMH is a putative virulence determinant of V. mimicus. Some other enteropathogenic species such as $V$. cholerae non-O1/non-O139 and Vibrio fluvialis are known to produce orthologues of $\mathrm{VMH}^{20}{ }^{20}$ The results in this paper may suggest these orthologues also contribute to virulence of the enteropathogenic Vibrio species.

Acknowledgements This study was supported by a Grant-in-Aid for Scientific Research from Japan Society for the Promotion of Sciences.

\section{REFERENCES}

1) Shandera, W. X., Johnston, J. M., Davis, B. R. and Blake, P. A. (1983) Disease from infection with Vibrio mimicus, a newly recognized Vibrio species. Ann. Intern. Med., 99, 169-171.

2) Janda, J. M., Powers, C., Bryant, R. G. and Abbott, S. (1988) Current perspectives on the epidemiology and pathogenesis of clinically significant Vibrio spp. Clin. Microbiol. Rev., 1, 245-267.

3) Chowdhury, M. A. R., Aziz, K. M. S., Kay, B. A. and Rahim, Z. (1987) Toxin production by Vibrio mimicus strains isolated from human and environmental sources in Bangladesh. J. Clin. Microbiol., 25, 2200-2203.

4) Miyoshi, S., Sasahara, K., Akamatsu, S., Rahman, M. M., Katsu, T., Tomochika, K. and Shinoda, S. (1997) Purification and characterization of a hemolysin produced by Vibrio mimicus. Infect. Immun., 65, 1830-1835.

5) Shinoda, S., Nakagawa, T., Shi, L., Bi, K., Kanoh, Y., Tomochika, K., Miyoshi, S. and Shimada, T. (2004) Distribution of virulence-associated genes in Vibrio mimicus from clinical and environmental origins. Microbiol. Immunol., 48, 547-551.

6) Sultan, Z., Mizuno, T., Sakurai, A., Takata, N., Okamoto, K. and Miyoshi, S. (2007) Growth phase dependent activation of the precursor of Vibrio mimicus hemolysin (pro-VMH). J. Health Sci., 53, 430434.

7) Li, Y., Okamoto, K., Takahashi, E., Miyoshi, S., Shinoda, S., Tsuji, T. and Fujii, Y. (2005) A hemolysin of Vibrio mimicus (VMH) stimulates cells to produce ATP and cyclic AMP which appear to be secretory mediators. Microbiol. Immunol., 49,
73-78.

8) Takahashi, A., Miyoshi, S., Takata, N., Nakano, M., Hamamoto, A., Mawatari, K., Harada, N., Shinoda, S. and Nakaya, Y. (2007) Haemolysin produced by Vibrio mimicus activates two $\mathrm{Cl}^{-}$secretory pathways in cultured intestinal-like Caco-2 cells. Cell. Microbiol., 9, 583-595.

9) Nishibuchi, M., Kumagai, K. and Kaper, J. B. (1991) Contribution of the $t d h l$ gene of Kanagawa phenomenon-positive Vibrio parahaemolyticus to production of extracellular thermostable direct hemolysin. Microb. Pathog., 11, 453-460.

10) Miyoshi, S., Inami, Y., Moriya, Y., Kamei, T., Rahman, M. M., Yamamoto, S., Tomochika, K. and Shinoda, S. (1997) Characterization of a mutant of Vibrio vulnificus for heme utilization. FEMS Microbiol. Lett., 148, 101-106.

11) Chang, D. E., Smalley, D. J., Tucker, D. L., Leatham, M. P., Norris, W. E., Stevenson, S. J., Anderson, A. B., Grisson, J. E., Laux, D. C., Cohen, P. S. and Conway, T. (2004) Carbon nutrition of Escherichia coli in the mouse intestine. Proc. Natl. Acad. Sci. U.S.A., 101, 7427-7432.

12) Fabich, A. J., Jones, S. A., Chowdhury, F. Z., Cernosek, A., Anderson, A., Smalley, D., McHargue, J. W., Hightower, G. A., Smith, J. T., Autieri, S. M., Leatham, M. P., Lins, J. J., Allen, R. L., Laux, D. C., Cohen, P. S. and Conway, T. (2008) Comparison of carbon nutrition for pathogenic and commensal Escherichia coli strains in the mouse intestine. Infect. Immun., 76, 1143-1152.

13) Freter, R. and O'Brien, P. C. M. (1981) Role of chemotaxis in the association of motile bacteria with intestinal mucosa: chemotactic responses of Vibrio cholerae and description of motile nonchemotactic mutants. Infect. Immun., 34, 215-221.

14) Richardson, K. (1991) Roles of motility and flagellar structure in pathogenicity of Vibrio cholerae: analysis of motility mutants in three animal models. Infect. Immun., 59, 2727-2736.

15) Wang, J., Sasaki, T., Maehara, Y., Nakao, H., Tsuchiya, T. and Miyoshi, S. (2008) Variation of extracellular proteases produced by Vibrio vulnificus clinical isolates: genetic diversity of the metalloprotease gene $(v v p)$, and serine protease secretion by vvp-negative strains. Microb. Pathog., 44, 494-500.

16) Miyoshi, S., Nitanda, Y., Fujii, K., Kawahara, K., Li, T., Maehara, Y., Ramamurthy, T., Takeda, Y. and Shinoda, S. (2008) Differential gene expression and extracellular secretion of the collagenolytic enzymes by the pathogen Vibrio parahaemolyticus. FEMS Microbiol. Lett., 283, 176-181. 
17) Alam, M., Miyoshi, S., Tomochika, K. and Shinoda, S. (1997) Vibrio mimicus attaches to the intestinal mucosa by outer membrane hemagglutinins specific to polypeptide moieties of glycoproteins. Infect. Immun., 65, 3662-3665.

18) Alam, M., Miyoshi, S., Yamamoto, S., Tomochika, K. and Shinoda, S. (1996) Expression of virulencerelated properties by, and intestinal adhesiveness of, Vibrio mimicus strains isolated from aquatic environments. Appl. Environ. Microbiol., 62, 3871-
3874.

19) Alam, M., Miyoshi, S., Tomochika, K. and Shinoda, S. (1996) Purification and characterization of novel hemagglutinins from Vibrio mimicus: a 39-kilodalton major outer membrane protein and lipopolysaccharide. Infect. Immun., 64, 4035-4041.

20) Olson, R. and Gouaux, E. (2005) Crystal structure of the Vibrio cholerae cytolysin (VCC) pro-toxin and its assembly into a heptameric transmembrane pore. J. Mol. Biol., 350, 997-1016. 